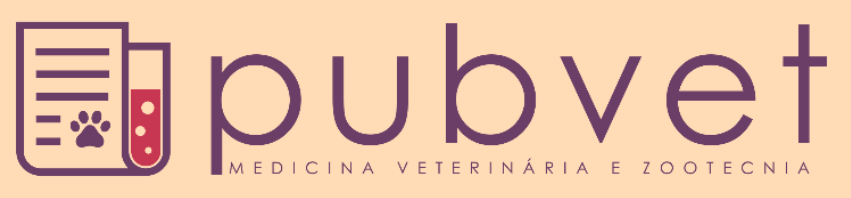

https://doi.org/10.31533/pubvet.v13n02a257.1-6

\title{
Particularidades reprodutivas da fêmea bovina: Revisão
}

\author{
Paulo Henrique Araújo Soares ${ }^{1 *}$ \& Fabiano Santos Junqueira ${ }^{2} \theta$
}

${ }^{1}$ Médico Veterinário, Centro Universitário de Formiga, Especialista em docência no ensino superior pela Faculdade de Educação São Luís. Formiga - MG ${ }_{2}^{2}$ Médico Veterinário, Doutor em Ciência Animal pela Universidade Federal de Minas Gerais e Docente do Centro Universitário de Formiga, MG *Autor para correspondência, E-mail: paulo.h.soares.2007@hotmail.com

Resumo. O conhecimento das características reprodutivas das fêmeas bovinas é imprescindível que médicos veterinários possam exercer trabalhos inerentes a reprodução. Neste sentido, o conhecimento anatômico permite ao médico veterinário observar as estruturas presentes no trato reprodutor bovino e a funcionalidade de tais estruturas. Outro ponto a ser destacado é a compreensão dos eventos presentes no ciclo estral e como estes fatos influem no comportamento da fêmea. Além disso, a dinâmica folicular se faz parte indispensável do estudo, haja vista, que a fisiologia ovariana é a base da reprodução com influências na produção de hormônios e na gametogênese. Nesta perspectiva, o presente estudo visa elencar diversas peculiaridades presentes na reprodução bovina através de uma revisão de literatura.

Palavras chave: Anatomia, ciclo estral, dinâmica folicular

\section{Reproductive features of the bovine female: Review}

\begin{abstract}
Knowledge of the reproductive characteristics of bovine females is essential for veterinarians to be able to perform work inherent to reproduction. In this sense, the anatomical knowledge allows the veterinarian to observe the structures present in the bovine reproductive tract and the functionality of such structures. Another point to be highlighted is the understanding of the events present in the estrous cycle and how these facts influence the behavior of the female. In addition, follicular dynamics are an indispensable part of the study, since ovarian physiology is the basis of reproduction with influences on the production of hormones and on gametogenesis. In this perspective, the present study aims at listing several peculiarities present in bovine reproduction through a literature review.
\end{abstract}

Keywords: Anatomy, estrous cycle, follicular dynamics

\section{Particularidades reproductivas de la hembra bovina: Revisión}

Resumen. El conocimiento de las características reproductivas de las hembras bovinas es imprescindible para que médicos veterinarios puedan ejercer trabajos inherentes a la reproducción. En este sentido, el conocimiento anatómico permite al médico veterinario observar las estructuras presentes en el tracto reproductor bovino y la funcionalidad de tales estructuras. Otro punto para destacar es la comprensión de los eventos presentes en el ciclo estral y cómo estos hechos influyen en el comportamiento de la hembra. Además, la dinámica folicular se hace parte indispensable del estudio, teniendo en cuenta, que la fisiología ovárica es la base de la reproducción con influencias en la producción de hormonas y en la gametogénesis. En esta perspectiva, el presente estudio apunta a enumerar diversas peculiaridades presentes en la reproducción bovina a través de una revisión de literatura.

Palabras clave: Anatomía, ciclo estral, dinámica folicular 


\section{Introdução}

Muitas particularidades estão envolvidas na composição anatômica e fisiológica do sistema reprodutor da fêmea bovina. O trato reprodutor é composto por diversas estruturas como: ovários, ovidutos, útero, cérvix uterina, vagina, vestíbulo da vagina e vulva (Hafez \& Hafez, 2004).

Em termos fisiológicos as fêmeas bovinas se apresentam como poliéstricas não sazonais, com ciclos estrais regulares intervalados em 21 dias. Em condições fisiológicas normais o ciclo possui quatro fases: proestro, estro, metaestro e diestro (Benites \& Baruselli, 2011). Além disso, os ovários representam órgãos de relevante estudo, haja vista, que tal órgão está envolvido na endocrinologia reprodutiva e na gametogênese. Neste sentido, a compreensão da dinâmica folicular é indispensável para médicos veterinários que buscam trabalhar com a reprodução bovina (Hafez \& Hafez, 2004).

Neste contexto, o presente estudo visa oferecer um material de estudo para profissionais que se interessam pela reprodução bovina pela revisão bibliográfica.

\section{Anatomia do trato reprodutor bovino}

O trato reprodutor das fêmeas bovinas é composto por: ovários, ovidutos, útero, cérvix uterina, vagina, vestíbulo da vagina e vulva (Hafez \& Hafez, 2004). Os ovários são órgãos pares, que se localizam até o terço ventral da cavidade abdominal, cranialmente ao púbis. Possuem formato elíptico (forma de amêndoa), tendo como tamanho cerca de 1,5 a $5 \mathrm{~cm}$ de comprimento e 1 a $3 \mathrm{~cm}$ de diâmetro, sendo esta dimensão variável mediante a fase do ciclo estral, ao qual a fêmea se encontre. Estes órgãos são sustentados pelo mesovário, e irrigados pela artéria ovariana. Desempenha tanto função endócrina (devido à esteroidogênese), quanto função exócrina (devido à produção de gametas). Os ovários possuem uma zona medular (estroma), na qual se localiza nervos, vasos sanguíneos e linfáticos, e uma zona cortical (região parenquimatosa) na qual se desenvolvem os folículos ovarianos (Arthur \& Santos, 1979; Ball \& Peters, 2006; König \& Liebich, 2011).

Os ovidutos ou tubas uterinas estão em íntima relação anatômica com os ovários. Estes órgãos são pares e são sustentados pela ramificação do ligamento largo, denominado mesossalpinge. O oviduto é dividido em três estruturas funcionais. A primeira delas é chamada de infundíbulo, no qual se localiza as fímbrias (com forma de franjas), que têm por função captar os oócitos liberados pelo ovário. No segmento médio do oviduto, se encontra a ampola, na qual ocorre o processo de fertilização. Conectado a ampola, está o istmo, estrutura que se liga ao corno uterino e capta os espermatozoides, realizando contrações para levá-los até a ampola. Cada oviduto possui 20 a $30 \mathrm{~cm}$ de comprimento e 2 a $3 \mathrm{~mm}$ de diâmetro (Ball \& Peters, 2006; Hafez \& Hafez, 2004). O útero é constituído por dois cornos uterinos, um corpo e uma cérvix (colo), e quando esticado tem formato de Y. O útero é constituído por três camadas: a camada mais interna mucosa (endométrio), camada muscular (miométrio) e a camada externa serosa (perimétrio). Os ruminantes possuem no endométrio estruturas denominadas carúnculas que tem por função: fixar a placenta durante a gestação. O útero é sustentado pelo mesométrio e irrigado pela artéria uterina média. O tamanho do útero é variável, pois depende de alguns fatores, tais como: a idade da fêmea e a quantidade de partos. No entanto estima-se, que um útero não gravídico, tem aproximadamente nos cornos 20 a $40 \mathrm{~cm}$ de comprimento e 1,2 a $4 \mathrm{~cm}$ de diâmetro (Arthur \& Santos, 1979; Ball \& Peters, 2006; König \& Liebich, 2011). A cérvix é uma estrutura fibrosa que possui uma espessa parede. Ela funciona como barreira entre a vagina e o útero. Seu lúmen abre-se somente no cio ou no nascimento. Nos bovinos, a cérvix possui formato transverso sendo dividida geralmente, por quatro pregas, denominados anéis (König \& Liebich, 2011). Caudal a cérvix se encontra a vagina, que possui uma superfície epitelial, uma camada muscular e uma camada serosa. Ela representa o órgão copulatório das fêmeas bovinas. O lúmen da vagina diminui na porção cranial pela projeção do colo uterino, formando o fórnice vaginal (Hafez \& Hafez, 2004; König \& Liebich, 2011).

Outro componente do trato reprodutor das fêmeas bovinas é o vestíbulo da vagina. A junção entre a vagina e o vestíbulo é apontada pelo orifício uretral e comumente por uma saliência (o hímen vestigial). Há casos de vacas, que o hímen é tão proeminente que gera interferência na cópula. O vestíbulo mede aproximadamente $10 \mathrm{~cm}$ (Hafez \& Hafez, 2004). A vulva é composta por lábios vulvares. Ela compreende a abertura externa do trato reprodutivo. Os lábios vulvares se unem conjuntamente nos 
ângulos dorsal (arredondado) e ventral (agudo). Ela permite a entrada do pênis do reprodutor ou a pipeta de inseminação (Arthur \& Santos, 1979; Ball \& Peters, 2006; König \& Liebich, 2011).

\section{Ciclo estral bovino}

O ciclo estral envolve o intervalo de um estro ao outro, sendo dividido em quatro estágios: proestro, estro, metaestro e diestro (Mies Filho, 1987). Um ciclo regular de vacas adultas, dura cerca de aproximadamente 21 dias, sendo a espécie bovina poliéstrica (Benites \& Baruselli, 2011). O ciclo estral está dividido em fase luteal e fase folicular. A fase folicular está sobre efeito do hormônio estrógeno e compreende o proestro e estro. Já a fase luteal está sobre o efeito da progesterona, sendo esta fase representada pelo metaestro e diestro (Ball \& Peters, 2006). Hafez \& Hafez (2004) expõem que o ciclo estral é regulado mediante mecanismos endócrinos e neuroendócrinos, especialmente pela ação dos hormônios hipotalâmicos, as gonadotrofinas e os esteroides secretados pelas gônadas.

O primeiro ciclo estral se dá quando a fêmea entra na puberdade, pois é nesta etapa que ocorre o primeiro estro e a primeira ovulação. No entanto, o estabelecimento do momento em que a fêmea irá entrar em puberdade é muito variável, uma vez que depende de fatores ambientais e genéticos, tais como: raça e peso corporal (Ball \& Peters, 2006).

O proestro possui duração média de dois a três dias, e é caracterizado pelo déficit de progesterona e aumento do estradiol sérico. Este fato se deve ao avanço do desenvolvimento folicular, devido a maciça liberação de GnRH e consequentemente de gonadotrofinas, acompanhados de lise do corpo lúteo. Ao exame clínico é possível observar os seguintes sinais na inspeção: vulva levemente edemaciada, vestíbulo avermelhado e baixa secreção de muco. Além disso, na palpação retal é possível identificar: útero com boa contratilidade, ovários com folículos de 15 a $20 \mathrm{~mm}$ de diâmetro e corpo lúteo firme e em regressão com 10 a 20 mm (Dirksen et al., 2013; Grunert et al., 2005).

O estro é o estágio do ciclo estral, no qual haverá manifestação de receptividade sexual, por consequência dos altos níveis de estrógeno sérico. As vacas em cio (estro) irão manifestar postura submissa para serem montadas pelo touro e/ou por outras vacas do rebanho, irão apresentar atividade aumentada, mugidos constantes, vulva edemaciada, mucosa vestibular e vaginal hiperêmica, secreção de muco vaginal de cor clara e vestígios deste na cauda e quartos traseiros. Na palpação retal é observado: útero fortemente contraído e folículos ovarianos com até $25 \mathrm{~mm}$ de diâmetro. A duração média do estro é 12 a 18 horas, sendo este valor variável, haja vista, que vários fatores podem influenciálo, como por exemplo, a raça. Animais zebuínos possuem uma duração mais curta de cio que animais europeus (Ball \& Peters, 2006; Dirksen et al., 2013; Thompson, 2006).

O estágio seguinte é denominado metaestro, que têm duração média de dois a três dias. Um dos eventos que ocorre no metaestro é a ovulação, que é desencadeada em média 12 horas após o termino do estro. As células do folículo ovariano após a ovulação, irão se reorganizar e multiplicar, dando origem ao corpo lúteo, responsável principalmente, pela produção de progesterona. A fêmea neste estágio, não aceita mais ser montada e pode ser avaliado em alguns animais, secreção de muco sanguinolento e vestígios deste na cauda e quartos traseiros. Na palpação retal, o útero se apresenta com baixa contratilidade e o ovário com um pequeno corpo lúteo macio, sendo este não detectável na palpação retal na maioria dos casos (Dirksen et al., 2013; Grunert et al., 2005).

O diestro abrange o maior período do ciclo estral, sendo este estágio caracterizado pela intensa atividade do corpo lúteo, que secreta alta concentração de progesterona. A mucosa vestibular e vaginal se apresenta rosa pálido e não muito úmida, enquanto a cérvix se apresenta 'fechada' pela formação de um tampão mucoso. Quanto aos achados na palpação retal, avalia-se que o útero possui pouca contratilidade, corpo lúteo detectável, por estar com até $30 \mathrm{~mm}$ de diâmetro e ao final do diestro é possível palpar folículos ovarianos em estágios iniciais de até $14 \mathrm{~mm}$ (Benites \& Baruselli, 2011; Grunert et al., 2005). Ao fim do diestro, as concentrações de progesterona decrescem - por efeito da lise do corpo lúteo, mediada pela $\mathrm{PGF}_{2} \alpha$ - levando ao início de um novo ciclo estral. No entanto, se houver presença de um concepto, a luteólise é bloqueada e a gestação prossegue (Ball \& Peters, 2006).

Alguns fatores impedem que o ciclo estral ocorra normalmente, deixando a fêmea em um quadro de anestro. Este quadro se define por uma inatividade sexual, ou seja, a fêmea não irá manifestar comportamento de estro, apresentando falha no desenvolvimento de folículos ovarianos. O anestro pode 
ser por uma insuficiência de gonadotrofinas, como por exemplo, nos episódios de mudanças estacionais, freemartinismo, ovários císticos, deficiências nutricionais e em alguns animais pela lactação. Além disso, o anestro pode ser desencadeado por persistência do corpo lúteo, em casos de gestação, mumificação e piometra (Jainudeen \& Hafez, 2004).

\section{Dinâmica folicular}

Os ovários são os órgãos responsáveis pelo desenvolvimento dos folículos e consequentemente dos oócitos (Espey, 1978). Hafez \& Hafez (2004) discorrem que "o folículo ovariano é uma unidade fisiológica equilibrada cujas estruturas e funções dependem de fatores extracelulares, como as gonadotrofinas e um complexo sistema de interações interfoliculares".

A classificação dos folículos ovarianos se dá em folículos pré-antrais e folículos antrais. Os folículos pré-antrais englobam os folículos primordiais, primários e secundários, já os folículos antrais têm como representantes os folículos terciários e os folículos de Graaf (pré-ovulatórios). Somente os folículos antrais possuem total dependência de gonadotrofinas (FSH e LH) para se desenvolverem, sendo que o crescimento dos folículos pré-antrais está condicionado a fatores intra ovarianos e locais (Magalhães et al., 2012).

Os folículos primordiais representam o estoque de folículos constituídos durante a fase fetal, se desenvolvendo durante a fase de vida reprodutiva. Eles são formados no feto entre 150 e 180 dias de gestação. Eles ficam em estado quiescente, com presença de células denominadas pré-granulosa, envolvidas por uma membrana basal. Os oócitos permanecem no estágio de prófase da primeira divisão meiótica, sem zona pelúcida. Não há suprimento sanguíneo para tais folículos e sua nutrição acontece por difusão (Benites \& Baruselli, 2011; Moraes, 2014). Os folículos primordiais possuem células epiteliais planas, e quando se transformam em folículos primários este epitélio se torna isoprismático com uma camada de células da granulosa em forma cuboide. Com efeito, os folículos primários terão alcançado um diâmetro de $100 \mu \mathrm{m}$, com início da constituição da zona pelúcida do oócito (König \& Liebich, 2011; Lima-Verde et al., 2011). Quando o desenvolvimento folicular atinge a fase de folículo secundário, há presença de uma zona pelúcida bem definida e células foliculares (granulosa, teca interna e externa) em intensa atividade mitótica. Nesta fase, os folículos já alcançaram um diâmetro médio de $200 \mu \mathrm{m}$ e se tornam responsivos às gonadotrofinas FSH e LH (Almeida, 1999; Lima-Verde et al., 2011). Após esta fase, os folículos secundários se desenvolvem e forma uma cavidade denominada antro, preenchida por um líquido, atingindo um diâmetro de $400 \mu \mathrm{m}$. Neste estádio, eles são denominados folículos terciários, possuindo células da granulosa cuboides em diversas camadas, além de células da teca interna e externa, da lâmina basal e das células do cumulus oophorus (Leitão et al., 2009). Por fim, ao receber estímulos para desenvolvimento, os folículos se tornam maduros e um do montante que foram selecionados atinge o papel de dominante alcançando o status de folículo pré-ovulatório, possuindo este uma cavidade (antro) maior (Leitão et al., 2009; Moraes, 2014).

O desenvolvimento folicular de fêmeas bovinas é realizado por meio de ondas foliculares. Em vacas é descrito a existência de três ondas de desenvolvimento folicular por ciclo. Todavia, isto não é uma regra, haja vista, que algumas fêmeas apresentam apenas duas ondas, enquanto outras apresentam quatro ondas (Noseir, 2003). Mies Filho (1987) a primeira onda de desenvolvimento folicular inicia-se logo após a ovulação (dia 0), a segunda no dia oito ou nove do ciclo estral e a terceira onda culminando no dia 15 ou 16. Cada onda de desenvolvimento folicular possui quatro estágios: recrutamento, seleção, dominância e atresia folicular ou ovulação (Diskin et al., 2002). O processo de recrutamento folicular é realizado por meio da mobilização de vários folículos antrais com diâmetro médio de $3 \mathrm{~mm}$. Para que ocorra o recrutamento folicular é necessário que haja um aumento de FSH, proporcionando assim o crescimento dos folículos recrutados (Roche, 2004).

No estágio de seleção, apenas alguns dos folículos recrutados da onda são selecionados para se desenvolverem. Todos os folículos recrutados podem ser selecionados, porém somente determinados folículos atingem está capacidade, pois adquirem um diâmetro médio de $8,5 \mathrm{~mm}$. Nesta fase há um processo de divergência, que consiste na diferenciação entre o futuro folículo dominante dos folículos restantes. A divergência possui como característica a baixa concentração sérica de FSH, sendo este fato consequência da alta produção de estrógeno e inibina pelo folículo de maior diâmetro. Esta baixa de FSH não prejudica o folículo dominante, pois este adquire capacidade de responder aos estímulos 
proporcionados pelo LH (Beg \& Ginther, 2006). O folículo dominante além de possuir um tamanho maior, possui também uma elevada concentração de estradiol e vários receptores de LH. Nesta perspectiva, o folículo dominante secreta mais que $80 \%$ de estradiol e $55 \%$ de inibina em relação ao folículo de estágio anterior (Moraes, 2014).

Um dos efeitos do estradiol é a formação de receptores adicionais de FSH sobre as células da granulosa. Todavia, à medida que estas células são estimuladas, a produção de inibina é aumentada e há feedback negativo sobre a secreção de FSH. Desta maneira, haverá uma maior liberação de LH que resultará no pico pré-ovulatório (Davidson \& Stabenfeldt, 2014). Os demais folículos que não alcançam o status de dominante entram em estado de atresia. A atresia folicular compreende diversas mudanças morfológicas, bioquímicas e histológicas que culminam em degeneração. Ela está associada à insuficiência de receptores gonadotróficos nas células foliculares (Hafez \& Hafez, 2004c).

Para que haja a ovulação o folículo dominante deve passar pelo processo de maturação, que é realizado através das gonadotrofinas, em especial o LH. O LH irá se ligar nos receptores das células da teca interna, estimulando a síntese de andrógenos. Os andrógenos produzidos são encaminhados para as células da granulosa por difusão. Estas células ao receberem os estímulos do FSH irão aumentar a atividade da aromatase, que provocará a conversão de andrógenos em estrógeno (Buratini Júnior, 2007).

A partir da onda pré-ovulatória de LH, em média 24 horas antes da ovulação, ocorre mudanças críticas no folículo de Graaf que culminam na liberação do oócito. Ressalta-se que esta onda préovulatória é induzida pelo estradiol, que propicia feedback positivo sobre o hipotálamo na secreção pulsátil de GnRH. Neste sentido, quando a alta concentração de GnRH alcançar a adenohipófise, irá estimular a liberação de LH, haja vista, que a inibina estará impedindo a liberação de FSH (Davidson \& Stabenfeldt, 2014). Moraes (2014) demonstram que após a ovulação as células foliculares sofrem intensas alterações morfológicas, marcadas por angiogênese, proliferação de células fibroblásticas e hipertrofia das células luteais. As células luteais são distinguidas em grandes e pequenas. As células luteais grandes tem origem das células da granulosa, e as pequenas são de origem das células da teca. As células luteais constituirão o corpo lúteo que produzirá progesterona. A progesterona terá como principal efeito, realizar a manutenção da gestação. O LH é um importante agente para a manutenção do corpo lúteo (Davidson \& Stabenfeldt, 2014). Em fêmeas não gestantes, haverá o processo conhecido como luteólise. Este processo se dá, quando a prostaglandina $\mathrm{F}_{2} \alpha\left(\mathrm{PGF}_{2} \alpha\right)$ entra em contato com as células luteais e provocam a apoptose destas células. Nesta perspectiva, o corpo lúteo ao se degenerar é denominado corpo albicans, o qual não terá eficiência na produção de progesterona (Moraes, 2014).

\section{Considerações finais}

Com base no presente exposto é possível observar que são muitos os aspectos relacionados a reprodução bovina. Tais aspectos devem ser considerados pelos médicos veterinários que estão inseridos na prática clínica, cirúrgica ou de manipulação do ciclo estral de bovinos. Nesta perspectiva, o trabalho será realizado com maior coerência e assertividade pelos profissionais.

\section{Referências bibliográficas}

Almeida, J. M. (1999). Embriologia veterinária comparada. Rio de Janeiro, Brasil: Gunabara Koogan.

Arthur, G. H. \& Santos, O. R. F. (1979). Reprodução e obstetrícia em veterinária. Rio de Janeiro, Brasil: Guanabara Koogan.

Ball, P. J. H. \& Peters, A. R. (2006). Reprodução em bovinos. São Paulo, São Paulo, Brasil: Roca.

Beg, M. A. \& Ginther, O. J. (2006). Follicle selection in cattle and horses: role of intrafollicular factors. Reproduction, 132(3), 365-377.

Benites, N. R. \& Baruselli, P. S. (2011). Medicamentos empregados para sincronização do crescimento folicular e da ovulação para transferência de embriões. In H. S. Spinosa, S. L. Górniak \& M. M. Bernardi (Eds.), Farmacologia aplicada à medicina veterinária (pp. 329-344). Rio de Janeiro, Brasil: Guanabara Koogan.

Buratini Júnior, J. (2007). Controle endócrino e local da foliculogênese em bovinos. Revista brasileira de Reprodução Animal, 31, 190=196. 
Davidson, A. P. \& Stabenfeldt, G. H. (2014). Controle do desenvolvimento gonadal e dos gametas. In B. G. Klein (Ed.), Tratado de fisiologia veterinária (Cunningham) (pp. 408-415). Rio de Janeiro, Brasil: Elsevier.

Dirksen, G., Gründer, H. D. \& Stöber, M. (2013). Exame Clínico dos Bovinos. Rio de Janeiro: Guanabara Koogan.

Diskin, M. G., Austin, E. J. \& Roche, J. F. (2002). Exogenous hormonal manipulation of ovarian activity in cattle. Domestic Animal Endocrinology, 23(1-2), 211-228.

Espey, L. L. (1978). Ovarian contractility and its relationship to ovulation: a review. Biology of Reproduction, 19(3), 540-551.

Grunert, E., Birgel, E. H. \& Vale, W. G. (2005). Patologia e clínica da reprodução dos animais mamíferos domésticos: ginecologia: Varela.

Hafez, B. \& Hafez, E. (2004). Reprodução Animal (Vol. 1, pp. 513): Manole: São Paulo, Brasil.

Jainudeen, M. R. \& Hafez, E. S. E. (2004). Bovinos e Bubalinos. In E. S. E. Hafez \& B. Hafez (Eds.), Reprodução Animal (pp. 159-167). Barueri, São Paulo, Brasil: Manole, 2004.

König, H. E. \& Liebich, H.-G. (2011). Anatomia dos Animais Domésticos: Artmed Editora.

Leitão, C. C. F., Brito, I. R., Frota, I. M. A. \& Silva, J. R. V. (2009). Importância dos fatores de crescimento locais na regulação da foliculogênese ovariana em mamíferos. Acta Scientiae Veterinariae, 37(3), 215-224.

Lima-Verde, I. B., Rossetto, R. \& Figueiredo, J. R. (2011). Influencia dos hormônios esteroides na foliculogênese. Revista Brasileira de Reprodução Animal, 35(4), 472-482.

Magalhães, D. M., Sales, E. T., Padilha, R. T., Silva, T. F., Tonioli, R. \& Figueiredo, J. R. (2012). Hormônio do crescimento $(\mathrm{GH})$ e fator de crescimento semelhante à insulina-I (IGF-I): importantes reguladores das foliculogêneses in vivo e in vitro. Revista Brasileira de Reprodução Animal, 36(1), $32-38$

Mies Filho, A. (1987). Reprodução dos animais (Vol. 1). Porto Alegre: Livraria Sulina Editôra.

Moraes, J. C. F. (2014). Controle do estro e da ovulação em ruminantes. In P. B. D. Gonçalves, J. R. Figueiredo \& V. J. F. Freitas (Eds.), Biotécnicas aplicadas à reprodução animal (pp. 33-56). São Paulo, Brasil: Roca.

Noseir, W. M. B. (2003). Ovarian follicular activity and hormonal profile during estrous cycle in cows: the development of 2 versus 3 waves. Reproductive Biology and Endocrinology, 1(1), 1-6.

Roche, J. F. (2004). Follicular waves in cattle. Veterinary Research Communications, 28(1), 107-110.

Thompson, F. (2006). Reprodução em mamíferos do sexo feminino. In W. Reece \& Dukes (Eds.), Fisiologia dos Animais Domésticos (pp. 644-669). Rio de Janeiro: Guanabara Koogan.

Recebido: 12 dezembro, 2018.

Aprovado: 29 dezembro, 2018

Publicado: 28 janeiro, 2018.

Licenciamento: Este artigo é publicado na modalidade Acesso Aberto sob a licença Creative Commons Atribuição 4.0 (CC-BY 4.0), a qual permite uso irrestrito, distribuição, reprodução em qualquer meio, desde que o autor e a fonte sejam devidamente creditados 